\title{
AN ANALYSIS OF INCOME DISTRIBUTION BETWEEN REGIONS FOR TURKEY
}

\author{
DOI: 10.17261/Pressacademia.2018.869
}

PAP- V.7-2018(22)-p.139-143

\section{Neslihan Fidan Kececi}

Istanbul University, School of Business, Quantitative Methods Department, Avcılar Campus, Istanbul, Turkey. neslihan@istanbul.edu.tr, ORCID: 0000-0003-3007-9963

\section{To cite this document}

Fidan Kececi, N. (2018). An analysis of income distribution between regions for Turkey. PressAcademia Procedia (PAP), V.7, p.139-143.

Permemant link to this document: http://doi.org/10.17261/Pressacademia.2018.869

Copyright: Published by PressAcademia and limited licenced re-use rights only.

\section{ABSTRACT}

Purpose- In this study, by using second order stochastic dominance criteria which is a new criterion compared to classical approaches, it is aimed to compare the distributions of the regions with different income levels in Turkey.

Methodology- Second order stochastic dominance (SSD) criteria provides comparison between the regions in terms of their income distribution based on Gini coefficient.

Findings- By using annualy equivalised household disposable income data from Turkish Statistical Institute (TUiK), between $2006-2016$ years, binary comparisons were made among the regions (NUTS-1) and it has been shown that certain regions dominate the some others in terms of income distribution in the period covered in the study. Also via same approach we observed that certain years are more effective in terms of Gini coefficient than other years.

Conclusion- SSD criteria is a measure that can be used in income distribution analysis. Therefore, in this study we tried to show that the SSD criteria provides more information than the Lorenz curve.

Keywords: Stochastic dominance, second order stochastic dominance, income distribution, Gini coefficient, Lorenz curve.

JEL Codes: C10, D31, D6

\section{TÜRKIYE BÖLGELER ARASI GELIR DAĞILIMI IÇIN BIR ANALIZ}

\section{ÖZET}

Amaç- Bu çalışmada, klasik yaklaşımlara göre yeni sayılabilecek bir ölçüt olan SSD kriteri ile, Türkiye'de farklı gelir düzeylerine ilişkin dağılımların bölgelerarası düzeyde karşılaştırılması amaçlanmaktadır.

Yöntem- İkinci dereceden stokastik baskınlık (SSD) kriteri Gini katsayısına dayanarak bölgeler arasında gelir dağılımı açısından karşılaştırma yapma olanağı sunmaktadır.

Bulgular- Türkiye İstatistik Kurumu (TUiK) yıllık Hanehalkı kullanılabilir gelir verileri kullanılarak, 2006-2016 yılları arasında İstatistiki Bölge Birimleri Sınıflamasına göre 12 bölge arasında (IBBS-1.Düzey) ikişerli karşılaştırmalar yapılmış ve belirli bölgelerin çalıșmada ele alınan dönemde diğerlerine göre gelir dağılımı açısından baskın olduğu gösterilmiştir. Aynı yöntem ile yine Gini katsayıları dikkate alınarak ilgili yıllarda kaydedilen katsayının yıllar arasındaki etkinliği de incelendiğinde, belirli yılların diğer yıllara göre Gini katsayısı açısından daha etkin olduğu gözlenmiştir.

Sonuç- SSD kriteri gelir dağılımı analizinde kullanılabilecek bir ölçüm aracıdır. Dolayısıyla bu çalışmada SSD kriterinin Lorenz eğrisine göre daha fazla bilgi sağladığı gösterilmeye çalışılmaktadır.

Anahtar Kelimeler: Stokastik baskınlık, ikinci dereceden stokastik baskınlık, gelir dağılımı, Gini katsayısı, Lorenz eğrisi. JEL Kodları: C10, D31, D6

\section{GíRiş}

Gelir Dağılımı; bir ülkede belirli dönemler içinde yaratılan gelirin fertler, hanehalkları veya üretim faktörleri arasında bölünmesidir (TUiK). Gelir Dağılımındaki eşitsizlik tüm ülkelerin çözmesi beklenen bir problemidir. Gelir; milli bir ekonomide belirli bir dönemde yeniden yaratılan mal ve hizmet değerlerinin toplamıdır. Buna toplam hasıla da denir. Hanehalkı ya da fert açşından gelir, üretime yapılan katkı karşılığında belirli bir sürede elde edilen değerlerin toplamı olarak tanımlanabilir. Hanehalkı geliri, emek karşılı̆ı alınan ücret ve maaşlar olabileceği gibi toprak kirası (rant), sermaye geliri (faiz) veya teşebbüs geliri (kar) şeklide de olabilir.

Hanehalkındaki her bir ferdin elde ettiği kişisel yıllık kullanılabilir gelirlerin toplamından, ilgili dönemde ödenen vergiler ve diğer hane veya kişilere yapılan düzenli transferler düşüldükten sonra hanehalkı kullanılabilir geliri'ne ulaşılmaktadır. Eşdeğer hanehalkı kullanılabilir geliri diğer bir değişle o hanehalkı için eşdeğer fert başına düşen gelir, hanehalkı toplam yıllık kullanılabilir gelirinin hanehalkının eşdeğer 
hanehalkı büyüklüğüne bölünmesiyle hesaplanmaktadır. Eşdeğerlik ölçeği ile farklı büyüklük ve bileşimlerdeki hanehalkları arasında karşılaştırma imkanı sağlanmaktadır. Eşdeğer hanehalkı kullanılabilir gelirleri kullanılarak hesaplanan Gelir dağılımı eşitsizlik göstergeleri arasında Gini katsayısı, Lorenz Eğrisi ve Yüzdelik Gruplar bulunmaktadır.

Gelir dağılımı eşitsizliğinde en çok kullanılan ölçütlerden biri de Gini katsayısıdır. Gini (1921) tarafından geliştirilen ve kendi adıyla anılan bu katsayı Gelir dağılımı eşitsizliğinin belirlenmesinde kullanılan objektif ölçütlerden biridir ve aşağıdaki şekilde tanımlanmaktadır:

$$
\text { Gini }=\frac{1}{2 n^{2} \bar{y}} \sum_{i=1}^{n} \sum_{j=1}^{n}\left|y_{i}-y_{j}\right|
$$

$$
\begin{aligned}
& y_{i}: i . \text { grubun toplam geliri } \\
& y_{j}: j \text {.grubun toplam geliri } \\
& n: \text { birim sayısı } \\
& \bar{y}: \text { tüm gelirlerin aritmetik ortalaması }
\end{aligned}
$$

Gini katsayısı 0 ile 1 arasında değerleri alır ve sıfır eşitsizliğin olmadığı durum olarak yorumlanır. Gini katsayısı, Lorenz eğrisi ile bu eğrinin en uç noktasında köşegeni bulunan bir karenin alanından faydalınarak bulunur. Eğri ile köşegen arasında kalan alanın köşegenin altında kalan ikizkenar üçgenin oranına eşittir ve oran büyüdükçe, dağılımdaki eşitsizlik artar. Gini katsayısı 0 ile 1 arasında değer alır. Bir toplumda, gelir adaletli olarak paylaşılmışsa, Gini katsayı "0"a eşit, toplumdaki gelirleri yalnız bir kişi almışsa, Gini katsayı "1" e eşit olmaktadır.

\section{Grafik 1: Lorenz Eğrisi}

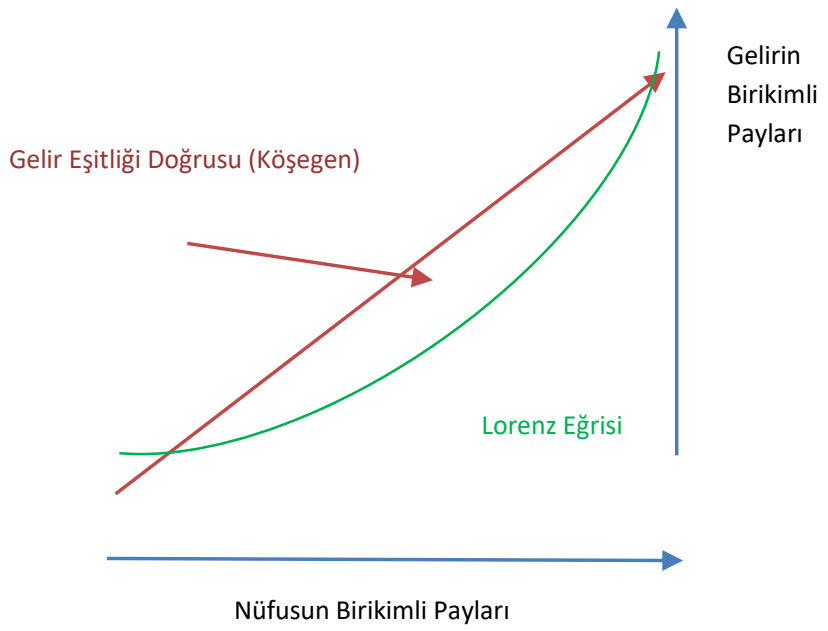

Lorenz Eğrisi (Lorenz, 1905); gelir ya da servetin nüfusa dağılımındaki eşitsizliği göstermekte kullanılan bir eğridir. Eğri bir karenin köşegeni ile uç noktalarda birleşir. Karenin dik ekseninde gelirin birikimli payları, yatay ekseninde ise nüfusun birikimli payları yüzdelik olarak gösterilir. Köşegen olarak elde edilen gelir doğrusu, gelirin nüfus arasında eşit dağıldığını gösterir. Lorenz eğrisi köşegenden uzaklaştıkça, gelir dağılımındaki eşitsizlik artmaktadır. Gini Katsayısı; Lorenz eğrisinden faydalanarak, 0 ile 1 arasındadır. 0'a yaklaşıyorsa gelir eşitsizliği azalıyor, büyüyor ve 1'e yaklaşıyorsa gelir eşitsizliği artıyor demektir. Eğer her yüzde 20'lik nüfus dilimi milli gelirin yüzde 20'sini almış oluyorsa Lorenz eğrisi köşegen ile yani tam eşitliğin sağlandığı doğru ile birleşir. Ancak nüfus dilimlerinin milli gelirden aldıkları paylar farklı olduğundan Lorenz Eğrisi tam eşitlik çizgisi altında oluşur. Lorenz eğrisi ile stokastik baskınlık arasındaki ilişki Atkinson (1970) tarafından ypılan çalışmada sunulmuştur. Lorenz eğrisine ilişkin uygulamaları, istatistiksel dağılım teorisindeki bazı varsayımları gözardı edebilen stokastik baskınlık kavramı ile inceleyen çalışmalar mevcuttur (Shorrocks, 1983; Davidson ve Duclos 2000; Kleiber, 2005; Le Breton, Michelangeli ve Peluso, 2012).

Ülkemizde kullanılan karşılaştırma analizlerinden birisi de Yüzdelik Gruplar analizidir. Yüzdelik hanehalkı/fert gruplarında ise hanehalkları kullanılabilir gelirine veya hanedeki tüm fertler eşdeğer hanehalkı kullanılabilir gelirlerine göre küçükten büyüğe doğru sıralanı; 20 gruba bölünerek yüzde $5^{\prime} l i k, 10$ gruba bölünerek yüzde $10^{\prime} l$ luk veya 5 gruba bölünerek yüzde $20^{\prime} l i k$ hanehalkı/fert grupları oluşturulur. Her bir grubun toplam gelirden aldıkları paylar gelir dağııımı eşitsizliği hakkında bilgi vermektedir. Yüzde paylar (P80/20) kişisel gelir dağılımını ölçmede kullanılan ölçütlerden biridir. \%20'lik fert/hanehalkı gruplarının toplam gelirden aldıkları paylara göre; son \%20'lik grubun toplam gelirden aldığı pay ilk \%20'lik grubun toplam gelirden aldığı pay’a oranlanarak, geliri daha yüksek olan son \%20'lik grubun, geliri düşük olan ilk \%20'lik gruba göre toplam gelirden kaç kat daha fazla pay aldığı görülmektedir.

Çalışmada Türkiye İstatistiki Bölge Birimleri Sınıflaması (IBBS) Düzey1 bölgeleri için TUiK tarafından yayınlanan Gini Katsayıları kullanılarak Stokastik Baskınlık kavramı ile birbirlerine olan üstünlükleri karşılaştırılmaktadır. Bunun için önce Stokastik Baskınlık kavramı açıklanmaktadır. Daha sonra 2006-2016 yılları arasında ilgili bölgeler için yayınlanan Gini Katsayıları kullanılarak yapılan analiz yeralmaktadır. 


\section{STOKASTIK BASKINLIK}

Stokastik baskınlık bir rastlantı değişkeninin dağılımından bağımsız olma özelliği taşıyan ve aslında dağılımı oluşturan değerlerin tamamını dikkate alan bir ölçüttür (Hanoch ve Levy, 1969). Çıkış noktasını kesin olarak belirlemek zor olsa da, Birinci Derece Stokastik Baskınlık (FSD) ve İkinci Derece Stokastik Baskınlık (SSD) koşullarından ilk kez 1969 yılında Hadar ve Russell (1969) tarafından bahsetmektedir. ${ }^{1}$

İstatistik olarak Stokastik Baskınlık, tercih edilen bir beklentinin birikimli dağılım değerinin hiçbir zaman ikinci tercih olanın birikimli dağılımını aşmaması durumudur ve bu tanım kısaca FSD tanımı olarak verilmektedir (Hadar ve Russell, 1969). ${ }^{2}$ Buna göre FSD ve SSD olarak Stokastik Baskınlık tanımları aşağıda verilmektedir.

\subsection{Birinci Derece Stokastik Baskınlık (FSD)}

Gerçel değerli bir $x$ raslantı değişkeni ve onun olasılık dağılımı $f$ için aşağıdaki koşullar sağlansın.

$$
\begin{gathered}
f(x)=P(X \leq x) \quad \forall x \in \mathcal{R} \\
F(x)=\int_{-\infty}^{x} f(y) d y
\end{gathered}
$$

$f$ ve $g$ gibi herhangi iki olasılık dağılımı için eğer $\forall x \in \mathcal{R}$ için $g(x) \geq f(x)$ sağlanıyorsa " $f g^{\prime} y e$ birini derece stokastik baskındır" denir ve

$$
f \succcurlyeq_{1} g
$$

ile gösterilir. Bu tanıma göre, $f^{\prime}$ in beklenen faydası $g^{\prime}$ nin beklenen faydasından küçük değilse $f g^{\prime}$ ye birinci derece stokastik baskındır (Hanoch ve Levy, 1969). FSD kavramı basitçe "stokastik baskınlık" olarak da bilinmektedir.

\section{2.ikinci Derece Stokastik Baskınlık (SSD)}

Eğer $\forall x \in \mathcal{R}$ için $G(x) \geq F(x)$ sağlanıyorsa; daha açık yazılacak olursa eğer

$$
\int_{-\infty}^{\eta} f(t) d t \leq \int_{-\infty}^{\eta} g(t) d t, \quad \forall \eta \in \mathcal{R}
$$

Sağlanıyorsa " $f g^{\prime}$ ye ikinci derece stokastik baskındır" denir ve

$$
f \geqslant 2 g \text { ile }
$$

gösterilir (Hadar and Russel, 1969). Bir raslantı değişkeni olan $x^{\prime}$ in bir eşik değer olarak $\eta$ hedefi için ikinci derece stokastik baskınlık ilişkisi

$$
E\left([\eta-f]_{+}\right) \leq E\left([\eta-g]_{+}\right), \quad \forall \eta \in \mathcal{R}
$$

olarak tanımlanır, burada $[\eta-f]_{+}=\max (0, \eta-f)^{\prime}$ dir (Ogryczak ve Ruszczysnki, 1999).

\subsection{Kesikli Senaryolarda İkinci Derece Stokastik Baskınlık}

Eğer yukarıdaki (6) eşitsizliğinde $\eta$ sonlu sayıdaki kesikli dağılımların senaryosunu gösterdiğini kabul edersek $T$ sayıda senaryolu $\boldsymbol{X}$ ve $\boldsymbol{Y}$ dağılımı için bu eşitsizlik

$$
E\left(\left[\eta_{t}-\boldsymbol{X}\right]_{+}\right) \leq E\left(\left[\eta_{t}-\boldsymbol{Y}\right]_{+}\right), \quad t=1,2, \ldots, T
$$

halini almaktadır (Rudolf ve Ruszczynski, 2008). Aynı zamanda optimizasyon probleminde birer kısıt da olan (7) eşitsizlikleri sırasıyla her bir $\eta_{1}, \eta_{2}, \ldots, \eta_{N}$ için $\boldsymbol{X}^{\prime}$ in $\boldsymbol{Y}^{\prime}$ ye ikinci derece stokastik baskın olduğunu ifade eder. Diğer bir ifadeyle $\boldsymbol{X}$ ve $\boldsymbol{Y}^{\prime}$ nin finansal getirilerin bir dağıımı olduğunu düşünürsek, $\boldsymbol{X}^{\prime}$ in belirlenen bir eşik değerinden daha az olan getirilerinin ortalaması $\boldsymbol{Y}^{\prime}$ ninkinden daha az ise $\boldsymbol{X}^{\prime}$ in $\boldsymbol{Y}^{\prime}$ ye ikinci derece stokastik baskındır.

\footnotetext{
1 Uluslararası yazımda bütünlükten kopmamak amacıyla bu çalışmada da Birinci Derece Stokastik Baskınlık ve İkinci Derece Stokastik Baskınlık kavramlarının sırasıyla FSD (First Order Stochastic Dominance) ve SSD (Second Order Stochastic Dominance) olmak üzere İngilizce kısaltmalarıyla tekrar edilmesi uygun görülmüştür.

2 Üçüncü derece stokastik baskınlık uygulama olarak esnek olmasa da teorik olarak ortaya konmuştur (Whitmore, 1970; Bawa, 1975). Bu çalışmada değinilmemektedir.
} 


\section{ANALIZ}

Gini katsayısı en temelde yüzdelik gruplamaların tek bir sayıya indirgenmiş halidir. Türkiye'de Gelir Dağılımına ilişkin Tablo 1'de verilen katsayılara bakıldığında Gini katsayısının zaman zaman küçülme gösterdiği görülmektedir.

Tablo 1: 2006-2016 Yılları Arası Gini Katsayısı, Türkiye

\begin{tabular}{|l|l|l|l|l|l|l|l|l|l|l|l|}
\hline Yıllar & 2006 & 2007 & 2008 & 2009 & 2010 & 2011 & 2012 & 2013 & 2014 & 2015 & 2016 \\
\hline $\begin{array}{l}\text { Gini } \\
\text { Katsayısı }\end{array}$ & 0.428 & 0.406 & 0.405 & 0.415 & 0.402 & 0.404 & 0.402 & 0.4 & 0.391 & 0.397 & 0.404 \\
\hline
\end{tabular}

Çalışmada Türkiye iBBS Düzey1 bölgeleri için 2006-2016 yılları arası Gelir Dağılımı İstatistiklerine dayanarak, eşdeğer hanehalkı kullanılabilir gelire göre hesaplanan Gini Katsayıları kullanıımıştı. Dolayısıyla Gini Katsayıları 11 ardışık yıl için 12 Bölge olarak dikkate alındığında veri 11 satır 12 sütun boyutunda bir matris büyüklüğündedir. En küçük Gini Katsayısı değeri 0,309 en büyük değeri 0,436'dır ve ortalama değeri $0,375^{\prime}$ tir (TUiK, Gelir Dağııımı ve Yaşam Koşulları İstatistikleri).

Tablo 2 Gini Katsayıları ile bölgelerin birbirlerine göre stokastik baskınlıkları hesaplanmaktadır. Tablo 2'ye bakıldığında sütunlardan yola çıkılarak yorum yapılabilmektedir. Buna göre 1. Bölge olarak İstanbul bölgesi sütunu bize İstanbul'un 12 bölge içerisinde 7 bölgeye Gelir Eşitsizliği açısından baskın (daha adaletli gelir dağııımı sağlayabilen) bölge olduğu anlaşılmaktadır. Örneğin İstanbul'da Akdenize göre Gelir dağılımı daha adaletlidir ancak Doğu Karadeniz İstanbul'dan daha adaletlidir. Görüldüğü gibi Doğu Karadeniz Bölgesi tüm bölgelerden daha adaletli gelir dağılımının sağlandığı bir bölge iken Akdeniz bölgesi Gelir eşitsizliğinin en fazla olduğu bölge olarak dikkati çekmektedir.

Tablo 2'de ayrıca Türkiye genelinin Gini Katsayılarına bakıldığında Türkiye geneli için bölgelerin herbirine göre daha adaletsiz bir gelir dağııımı okunmaktadır.

\section{Tablo 2: Türkiye IBBBS Düzey1 Bölgeleri İçin 2006-2016 Yılları Arası Stokastik Baskınlıklar}

\begin{tabular}{|l|c|cccccccccccc|}
\hline & TR & 1 & 2 & 3 & 4 & 5 & 6 & 7 & 8 & 9 & 10 & 11 & 12 \\
\hline 0. TR & $*$ & $\mathrm{~b}$ & $\mathrm{~b}$ & $\mathrm{~b}$ & $\mathrm{~b}$ & $\mathrm{~b}$ & $\mathrm{~b}$ & $\mathrm{~b}$ & $\mathrm{~b}$ & $\mathrm{~b}$ & $\mathrm{~b}$ & $\mathrm{~b}$ & $\mathrm{~b}$ \\
\hline 1. Istanbul & $\mathrm{d}$ & $*$ & $\mathrm{~b}$ & $\mathrm{~d}$ & $\mathrm{~b}$ & $\mathrm{~d}$ & $\mathrm{~d}$ & $\mathrm{~b}$ & $\mathrm{~b}$ & $\mathrm{~b}$ & $\mathrm{~d}$ & $\mathrm{~d}$ & $\mathrm{~d}$ \\
2. Batı Marmara & $\mathrm{d}$ & $\mathrm{d}$ & $*$ & $\mathrm{~d}$ & $\mathrm{~h}$ & $\mathrm{~d}$ & $\mathrm{~d}$ & $\mathrm{~d}$ & $\mathrm{~h}$ & $\mathrm{~b}$ & $\mathrm{~d}$ & $\mathrm{~d}$ & $\mathrm{~d}$ \\
3. Ege & $\mathrm{d}$ & $\mathrm{b}$ & $\mathrm{b}$ & $*$ & $\mathrm{~b}$ & $\mathrm{~d}$ & $\mathrm{~d}$ & $\mathrm{~b}$ & $\mathrm{~b}$ & $\mathrm{~b}$ & $\mathrm{~h}$ & $\mathrm{~d}$ & $\mathrm{~d}$ \\
4. Doğu Marmara & $\mathrm{d}$ & $\mathrm{d}$ & $\mathrm{h}$ & $\mathrm{d}$ & $*$ & $\mathrm{~d}$ & $\mathrm{~d}$ & $\mathrm{~d}$ & $\mathrm{~d}$ & $\mathrm{~b}$ & $\mathrm{~d}$ & $\mathrm{~d}$ & $\mathrm{~d}$ \\
5. Batı Anadolu & $\mathrm{d}$ & $\mathrm{b}$ & $\mathrm{b}$ & $\mathrm{b}$ & $\mathrm{b}$ & $*$ & $\mathrm{~d}$ & $\mathrm{~b}$ & $\mathrm{~b}$ & $\mathrm{~b}$ & $\mathrm{~h}$ & $\mathrm{~d}$ & $\mathrm{~b}$ \\
6. Akdeniz & $\mathrm{d}$ & $\mathrm{b}$ & $\mathrm{b}$ & $\mathrm{b}$ & $\mathrm{b}$ & $\mathrm{b}$ & $*$ & $\mathrm{~b}$ & $\mathrm{~b}$ & $\mathrm{~b}$ & $\mathrm{~b}$ & $\mathrm{~b}$ & $\mathrm{~b}$ \\
7. Orta Anadolu & $\mathrm{d}$ & $\mathrm{d}$ & $\mathrm{b}$ & $\mathrm{d}$ & $\mathrm{b}$ & $\mathrm{d}$ & $\mathrm{d}$ & $*$ & $\mathrm{~h}$ & $\mathrm{~b}$ & $\mathrm{~d}$ & $\mathrm{~d}$ & $\mathrm{~d}$ \\
8. Batı Karadeniz & $\mathrm{d}$ & $\mathrm{d}$ & $\mathrm{h}$ & $\mathrm{d}$ & $\mathrm{b}$ & $\mathrm{d}$ & $\mathrm{d}$ & $\mathrm{h}$ & $*$ & $\mathrm{~b}$ & $\mathrm{~d}$ & $\mathrm{~d}$ & $\mathrm{~d}$ \\
9. Doğu Karadeniz & $\mathrm{d}$ & $\mathrm{d}$ & $\mathrm{d}$ & $\mathrm{d}$ & $\mathrm{d}$ & $\mathrm{d}$ & $\mathrm{d}$ & $\mathrm{d}$ & $\mathrm{d}$ & $*$ & $\mathrm{~d}$ & $\mathrm{~d}$ & $\mathrm{~d}$ \\
10. Kuzeydoğu Anadolu & $\mathrm{d}$ & $\mathrm{b}$ & $\mathrm{b}$ & $\mathrm{h}$ & $\mathrm{b}$ & $\mathrm{h}$ & $\mathrm{d}$ & $\mathrm{b}$ & $\mathrm{b}$ & $\mathrm{b}$ & $*$ & $\mathrm{~d}$ & $\mathrm{~h}$ \\
11. Ortadoğu Anadolu & $\mathrm{d}$ & $\mathrm{b}$ & $\mathrm{b}$ & $\mathrm{b}$ & $\mathrm{b}$ & $\mathrm{b}$ & $\mathrm{d}$ & $\mathrm{b}$ & $\mathrm{b}$ & $\mathrm{b}$ & $\mathrm{b}$ & $*$ & $\mathrm{~b}$ \\
12. Güneydoğu Anadolu & $\mathrm{d}$ & $\mathrm{b}$ & $\mathrm{b}$ & $\mathrm{b}$ & $\mathrm{b}$ & $\mathrm{h}$ & $\mathrm{d}$ & $\mathrm{b}$ & $\mathrm{b}$ & $\mathrm{b}$ & $\mathrm{h}$ & $\mathrm{d}$ & $*$ \\
\hline Toplam & $\mathrm{d}$ & 7 & 9 & 5 & 10 & 3 & 1 & 8 & 8 & 12 & 3 & 2 & 4 \\
\hline
\end{tabular}

b: baskın bölge

$\mathrm{d}$ : baskın bölge değil

h: bölgelerden herhangi biri baskın değil

Eşdeğer hanehalkı kullanılabilir fert gelirine göre sıralı yüzde 5'lik gruplar itibarıyla yılık eşdeger hanehalkı kullanılabilir fert gelirinin dağılımı kullanılarak 2006-2016 yılları arasında stokastik baskınlıklara bakıldığında Tablo 3'te verilen sonuçlar elde edilmektedir. Yıllara göre Gini katsayıları karşılaştırıldığında ise 2006, 2007 ve 2011 yıllarının diğer hiçbir yıla göre daha adaletli bir gelir dağılımı sağlanamadığı ancak en fazla 2015 (diğer 6 yıla daha baskın) olmak üzere 2010 ve 2014 yıllaraının nispeten (5 yıla daha baskın) oldukları söylenebilmektedir.

Tablo 3. 2006-2016 Yılları Arası, Yıllara Göre Stokastik Baskınlıklar

\begin{tabular}{|l|ccccccccccc}
\hline & 2006 & 2007 & 2008 & 2009 & 2010 & 2011 & 2012 & 2013 & 2014 & 2015 & 2016 \\
\hline 2006 & b & h & b & b & b & h & b & b & b & b & b \\
2007 & h & b & h & h & b & h & b & b & b & b & h \\
2008 & h & h & b & h & b & h & h & h & b & b & h \\
2009 & d & h & h & b & b & h & h & h & h & h & h \\
2010 & d & h & h & h & b & d & h & h & h & h & h \\
2011 & h & h & h & h & b & b & b & b & b & b & h \\
2012 & d & h & h & h & h & d & b & h & h & b & h \\
2013 & d & h & h & h & h & d & h & b & h & h & h \\
2014 & h & h & h & h & h & d & h & h & b & h & h \\
2015 & d & h & h & h & h & d & h & h & h & b & h \\
2016 & h & h & h & h & h & h & h & b & b & b & b \\
\hline T & f & D & 1 & 1 & 5 & 0 & 3 & 4 & 5 & 6 & 1 \\
\hline
\end{tabular}

b: baskın yıl

d: baskın yıl değil

h: yıllardan herhangi biri baskın değil 


\section{SONUÇ}

SSD farklı dağıımların birbirlerine tercih edilebilirlikleri açısından karşılaştııııma sağlar. Tek bir ifadeyle bütünün değerlendirmesi yapılabilir. Elbetteki bölgelerarası gelir eşitsizliğinin analizinde pek çok farklı gösterge ve değişkenlerin kullanılması analizin tutarlıı̆ı̆ın arttıracaktır. Ancak Gini Katsayıları dikkate alınarak gelir dağııımı analizi için SSD analizi yapıldığında; bölgeler arası gelir eşitsizliğini önlemeye yönelik ne tür bir katkının olabileceğine dair ön durum değerlendirmesi yapmayı sağlar, bölgeye dair politikaların (teşvik, yatırım vs.) geliştirilmesine ışık tutar.

\section{KAYNAKLAR}

Atkinson, A. B. (1970). On the measurement of inequality. Journal of Economic Theory, 2, 244-263.

Le Breton, M., Michelangeli, A., Peluso, E. (2012). A stochastic dominance approach to the measurement of discrimination. Journal of Economic Theory, 147(4), 1342-1350.

Davidson, R., Duclos J. Y. (2000). Statistical inference for stochastic dominance and for the measurement of poverty and inequality. Econometrica, 68(6), 1435-1464.

Filiztekin, A., Çelik, M. A. (2010). Türkiye'de bölgesel gelir eşitsizliği. Megaron Journal, 5(3): 116-127.

Gini, C. (1921). Measurement of inequality of incomes. The Economic Journal, 31(121), 124-126.

Hadar, J., Russell, W. R. (1969). Rules for ordering uncertain prospects. The American Economic Review, 25-34.

Hanoch, G., Levy, H. (1969). The efficiency analysis of choices involving risk. The Review of Economic Studies, 36(3), pp.335-346.

Kleiber, C. (2005). The Lorenz curve in economics and econometrics. Invited paper, Gini-Lorenz Centennial Conference, Siena, May 23-26, 2005.

Lorenz, M. O. (1905). Methods of measuring the concentration of wealth. Quarterly Publications of the American Statistical Association, 9 (New Series, No. 70), 209-219.

Ogryczak, W., Ruszczyński, A. (1999). From stochastic dominance to mean-risk models: semideviations as risk measures. European Journal of Operational Research, 116(1), 33-50.

Shorrocks, A. F. (1983). Ranking income distributions. Economica, 50, 3-17.

TUiK (2018). Gelir dağılımı ve yaşam koşulları istatistikleri. Çevrimiçi (01.06.2018): http://www.tuik.gov.tr/PreTablo.do?alt id=1011 